\title{
INFLUÊNCIA DA AÇÃO ANTRÓPICA SOBRE PROCESSOS EROSIVOS E SOLAPAMENTO DE MARGENS NO BAIRRO NOVA SANTA MARTA E VILA BELA VISTA, SANTA MARIA-RS
}

\author{
Eduardo André Kaiser $^{(\mathrm{a})}$, Janderlei Velasquez Dal Osto ${ }^{(\mathrm{b})}$, Douglas Stefanello Facco ${ }^{(\mathrm{c})}$ \\ (a) Departamento de Geociências, Universidade Federal de Santa Maria, Kaiser-eduardo@ @otmail.com \\ (b) Departamento de Geociências, Universidade Federal de Santa Maria, janderleijunior@gmail.com \\ (c) Departamento de Geociências, Universidade Federal de Santa Maria, douglas.s.facco@ hotmail.com
}

\section{Eixo: GEOGRAFIA FÍSICA E DESASTRES NATURAIS}

\begin{abstract}
Resumo
O objetivo do presente trabalho é compreender as condições de risco encontradas em duas áreas de estudo localizadas em Santa Maria, RS, diante a influência do uso e ocupação da terra. A metodologia adotada compreendeu dois trabalhos de campo nas cabeceiras de drenagem no bairro Nova Santa Marta e a encosta do morro Cechella, onde foram efetuadas amostragens por observações sobre as condições de uso e ocupação da terra. Os resultados apontaram para alterações na dinâmica superficial tanto das cabeceiras como da encosta, principalmente associadas a modificações na estrutura e composição terreno, através da execução de cortes superficiais, retirada da cobertura vegetal e depósito de lixo. Deste modo os resultados encontrados apontam para necessidade de implementação de medidas e ações de planejamento com a finalidade de evitar futuros desastres.
\end{abstract}

Palavras chave: Suscetibilidade, cabeceira de drenagem, morro Cechella, ocupação urbana

\section{INTRODUÇÃO}

No Brasil, dentre os distintos processos ocorrentes no espaço físico do território, destacam-se: as inundações, as secas, erosão e os deslizamentos. Desses, os maiores prejuízos são caracterizados pelos eventos de inundação e o maior número de vítimas fatais ocorre como consequência dos deslizamentos. Segundo levantamentos do Instituto de Pesquisas Tecnológicas (IPT), num período de 20 anos (19882008), 1700 pessoas foram vitimadas por deslizamentos no Brasil (MACEDO, 2008).

Em grandes centros urbanos esses movimentos de massa assumem proporções catastróficas, uma vez que são fortalecidos pela ação antrópica através dos inúmeros cortes da encosta, aterros, depósitos de lixo, retirada da cobertura vegetal, modificações na drenagem, propiciando assim novas relações com fatores condicionantes naturais existentes, de ordem geomorfológica e geológica. 
Nessa linha, áreas de relevo acidentado ou regiões serranas tornam-se mais propícias à ocorrência de dois processos atuantes na desestabilização das encostas, um deles é a ação antrópica descrita anteriormente, manifestada me diferentes graus de alteração da paisagem, alguns mais evidentes que outros, como os taludes de corte que provocam a instabilidade da encosta devido o aumento nas tensões cisalhantes que atuam na superfície potencial de ruptura. $\mathrm{O}$ outro processo determinado pelos fenômenos naturais, que consiste na dinâmica externa da terra caracterizada pela degradação das rochas (intemperismo), transporte e deposição do material nas partes baixas do relevo, veiculadas pela ação da gravidade, vento, água superficial e águas sub superficiais (GUERRA, 2005).

A intervenção antrópica sobre as áreas de encosta, atualmente é marcada pelo fenômeno da urbanização, caracterizando a expansão das cidades devido ao parcelamento do solo sem diretrizes prévias de implantação, desfavorecendo assim populações de classe média baixa. Desta forma, a ocupação urbana ocorre de maneira irregular, popularmente denominada de invasão. Segundo o presidente da Federação Nacional dos Arquitetos e Urbanistas (FNA), esse tipo de problema é atribuído às desigualdades sociais herdadas de um longo processo histórico marcado pela ausência de políticas públicas eficientes (BIMBI, 2004).

Neste sentido, devido a área urbana do município de Santa Maria, Rio Grande do Sul dispor sobre o relevo acidentado característico da região serrana, a suscetibilidade a movimentos de massa encontra-se com maior probabilidade. Robaina et al (2001) discriminam 3 processos que determinam as áreas de risco geomorfológico para a cidade de Santa Maria: os processos de dinâmica fluvial evidenciados pelas inundações, alagamentos e erosões de margem ocorrentes nas bacias hidrográficas dos arroios Cadena, Ferreira e Vacacaí Mirim; as ocupações em encostas da formação Serra Geral, na porção Norte da cidade, sujeitas a movimentos de massa e os processos erosivos acelerados principalmente em áreas de cabeceira de drenagem dos arroios Cadena e Ferreira.

Para o caso de Santa Maria, desses processos a maior preocupação gira em torno das áreas sujeitas a movimentos de massa, principalmente nas regiões com declividade acentuada e as ocupações nas margens de rios. Diante essa contrapartida, o objetivo do presente trabalho é compreender as condições de suscetibilidade encontradas em duas áreas de estudo localizadas em Santa Maria, RS, diante a influência do uso e ocupação da terra.

\section{METODOLOGIA}




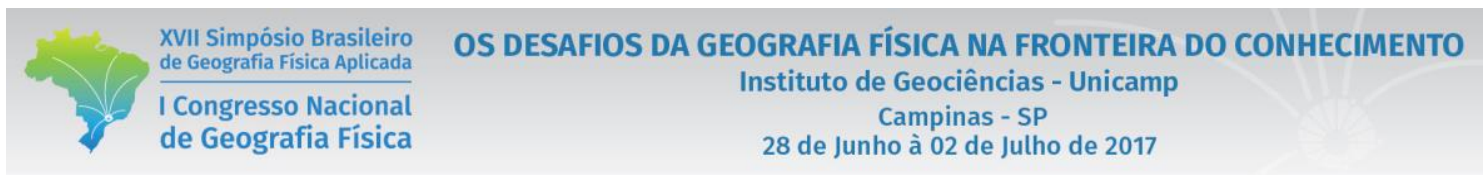

A metodologia do presente trabalho perfaz a descrição de procedimentos adotados para a compreensão das condições de risco encontradas na encosta oeste do morro Cechela (vila Bela Vista) e bairro Nova Santa Marta (cabeceiras de drenagem do arroio Cadena).

\subsection{Características gerais das áreas de estudo}

No contexto urbano de Santa Maria, uma das áreas cujo foi efetuado trabalho de campo compreende a Vila Bela Vista. Localizada no bairro Itararé, na porção nordeste da cidade, a vila está situada sobre a encosta oeste do morro Cechella.

A figura 1 mostra a localização da vila Bela Vista em relação ao município de Santa Maria e do estado do Rio Grande do Sul.

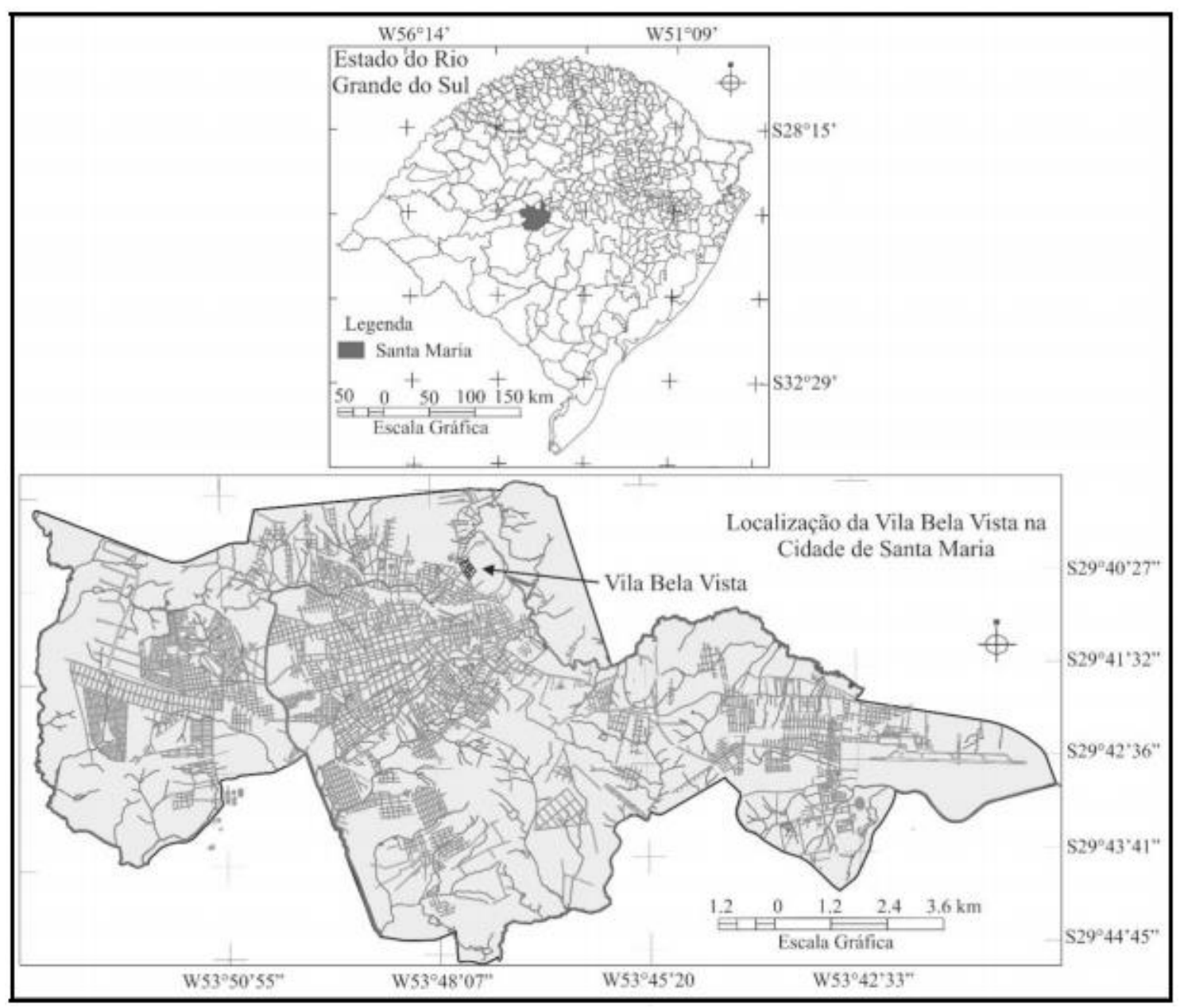

Figura 1. Localização da área de estudo correspondente a vila Bela Vista, bairro Itararé, Santa Maria. Fonte: DAL'ASTA, 2005. 
Sobre aspectos geomorfológicos e geológicos, a vila Bela vista está situada na base e na meia encosta do morro Cechella. Esse morro por sua vez, tem suas características associadas ao Rebordo do Planalto Sul Rio-grandense, considerado como morro testemunho. Geologicamente falando, o morro dispõe de um substrato formado por arenitos eólicos da Formação Botucatu e arenitos fluviais da Formação Caturrita e no topo rochas vulcânicas da Formação Serra Geral.

Por sua vez, o bairro Nova Santa Marta está localizado na porção noroeste do município de Santa Maria (Figura 2).

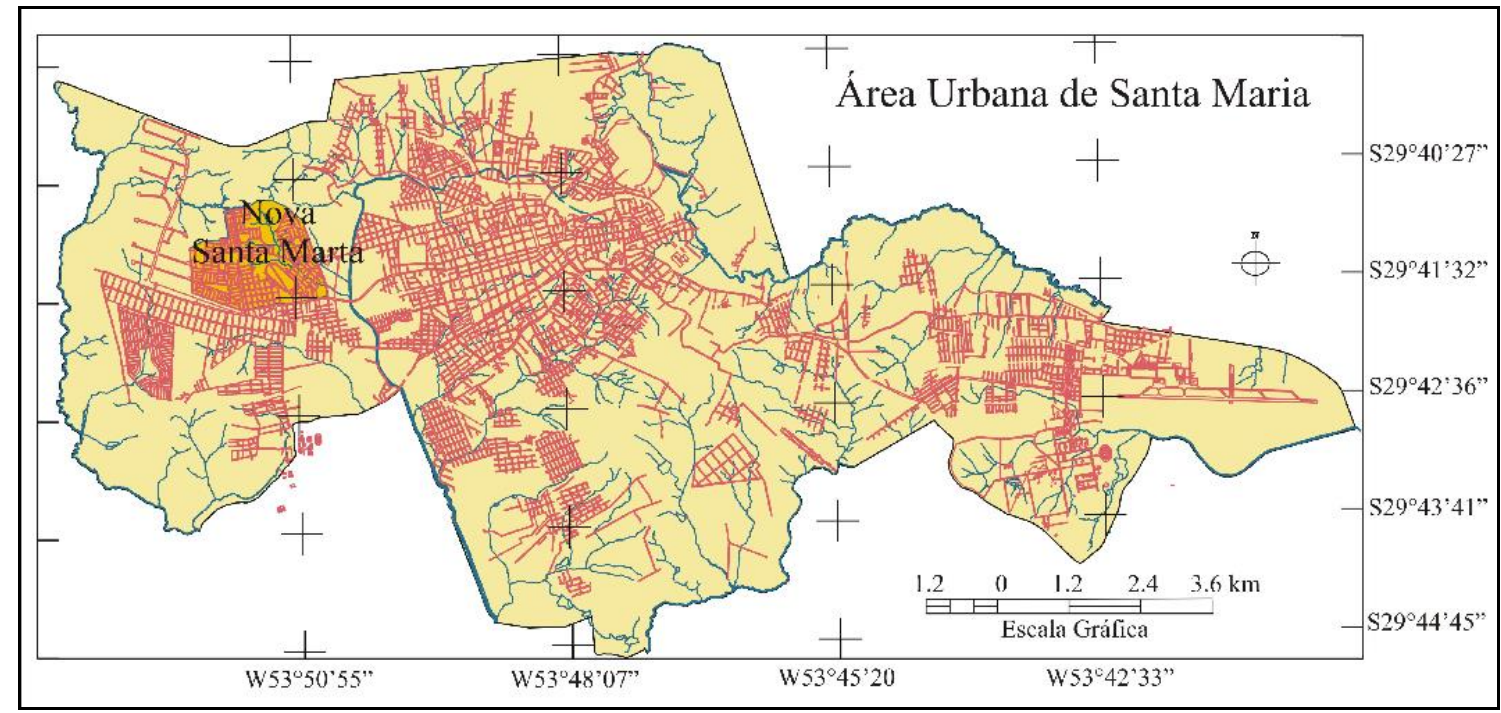

Figura 2. Localização do bairro Nova Santa Marta no município de Santa Maria. Fonte: RECKZIEGEL et al. 2005.

A base é formada por arenitos com seixo de quartzo e fragmentos de lamitos, altamente friáveis, sendo que a espessura que varia de 3 a 8 metros. O bairro Nova Santa Marta caracteriza-se por um alívio de colinas onde os processos erosivos estão associados à dinâmica da cabeceira, uma vez que a erosão profunda de ravina ocorre na área, cuja evolução é acelerada pela ação antrópica (RECKZIEGEL, 2005).

\subsection{Análise e descrição dos riscos}

Os procedimentos metodológicos que foram desenvolvidos durante os trabalhos de campo, tanto para a área de encosta do morro Cechella quanto para a as cabeceiras de drenagem do arroio Cadena, consistiram na realização de quatro amostragens definidas previamente em laboratório. Como critério para definição das estações, foram observadas características da superfície e possíveis áreas impactadas e em condições 
de suscetibilidade através do software Google Earth. Em trabalho de campo, as observações foram obtidas a partir de anotações e fotografias que representassem as características visualizadas no terreno, a partir de fatores pré-determinados.

Os fatores considerados para a identificação e observação dos processos de dinâmica superficial foram: Intensidade dos processos erosivos; Ocupação dos entornos (encostas); Forma da encosta; Descarte de material (resíduos domésticos); Exposição ou cobertura da terra; Formação geológica e; Características do substrato. Nesse contexto, foram retratadas também, moradias em situação de risco e quais fatores que pudessem desencadear esse risco considerando os processos superficiais característicos de cada área de estudo.

Segundo Christofoletti (1980) os movimentos de massa ou movimentos do regolito são definidos como todos os movimentos gravitacionais que promovem a movimentação de partículas ou partes do regolito pela encosta abaixo. Esse tipo de movimento considera apenas a gravidade como força responsável, desconsiderando os agentes de transporte como o vento, água, gelo e lava em fusão.

Hunt (1984) propôs um tipo de classificação (Tabela 1) dos movimentos de massa que parte das características e formas do deslocamento, dividindo assim os tipos de movimento em: 1-quedas, 2escorregamentos, 3 -avalanches, 4- corridas, 5- rastejos, 6- solifluxão e 7- movimentos complexos.

Sobre essa perspectiva, os movimentos de massa são classificados a partir de fatores como a natureza e velocidade do movimento, quantidade de água atuante e tipo de material. Sharpe (1938) propõe um esquema (Quadro 1) para classificação desses movimentos e fenômenos associados. 
Tabela 1. Classificação de rupturas de encosta, Hunt (1984).

\begin{tabular}{|c|c|c|}
\hline TIPO & FORMA & DEFINIÇÃO \\
\hline \multirow{2}{*}{1} & Queda livre & $\begin{array}{l}\begin{array}{l}\text { Repentino deslocamento de um ou mais blocos de solo ou rocha em queda livre } \\
\text { descendente. }\end{array} \\
\end{array}$ \\
\hline & Tombamento & $\begin{array}{l}\text { Tombamento de um bloco de rocha sobre um ponto apoiado, localizado abaixo do } \\
\text { seu centro de gravidade. }\end{array}$ \\
\hline \multirow{6}{*}{2} & Rotacional & $\begin{array}{l}\text { Movimento relativamente lento de um ou mais blocos, essencialmente coerentes } \\
\text { de solo, rocha ou mistura de rocha e solo ao longo de uma superficie de ruptura } \\
\text { bem definida, em forma de arco. }\end{array}$ \\
\hline & Planar ou translacional & $\begin{array}{l}\text { Movimento lento a rápido de um ou mais blocos, essencialmente coerentes de } \\
\text { solo ou rocha ao longo de uma superficie de ruptura bem definida, com forma } \\
\text { planar. }\end{array}$ \\
\hline & Deslizamento de blocos & Um ou mais blocos movendo-se ao longo de uma superficie planar. \\
\hline & Em cunha & $\begin{array}{l}\text { Um ou mais blocos movendo-se ao longo da intersecçăo de duas superficies } \\
\text { planares. }\end{array}$ \\
\hline & Espraiamento lateral & $\begin{array}{l}\text { Um número de blocos intactos movendo-se como unidades separadas com } \\
\text { diferentes deslocamentos. }\end{array}$ \\
\hline & $\begin{array}{l}\text { Deslizamento de massa } \\
\text { de solo e rocha }\end{array}$ & Mistura de solo e rocha movendo-se ao longo de uma superficie rochosa planar. \\
\hline 3 & $\begin{array}{l}\text { Rocha ou massa de } \\
\text { solo e rocha }\end{array}$ & $\begin{array}{l}\text { Rápido a muito rápido movimento de massa incoerente de rocha ou massa de } \\
\text { solo e rocha, ocorrendo ao longo de uma superficie de ruptura pouco definida. }\end{array}$ \\
\hline \multirow{4}{*}{4} & Massa de solo e rocha & \multirow{4}{*}{$\begin{array}{l}\text { Solo ou massa de solo e rocha movendo-se como um fluido viscoso, usualmente } \\
\text { terminando a longas distâncias além da zona de ruptura, resultando em } \\
\text { excessivas poro-pressóes (sub-classificada de acordo com o tipo de material). }\end{array}$} \\
\hline & Areia & \\
\hline & Silte & \\
\hline & $\begin{array}{ll}\text { Lama } \\
\text { Solo }\end{array}$ & \\
\hline 5 & & $\begin{array}{l}\text { Lento, imperceptivel movimento de solo ou mistura de solo e rocha encosta } \\
\text { abaixo. }\end{array}$ \\
\hline 6 & & $\begin{array}{l}\text { Porçø̃es rasas do regolito movendo-se encosta abaixo com taxas moderadas a } \\
\text { lentas em climas Ártico a sub-Ártico durante periodos de degelo acima de uma } \\
\text { superficie congelada do solo. }\end{array}$ \\
\hline 7 & & $\begin{array}{l}\text { Envolve a combinaçăo dos tipos acima, usualmente ocorrendo mudanças em } \\
\text { uma ou outra forma durante a ruptura com uma forma predominante. }\end{array}$ \\
\hline
\end{tabular}

Quadro 1. Classificação de movimentos de massa e fenômenos associados. Sharpe (1938). 


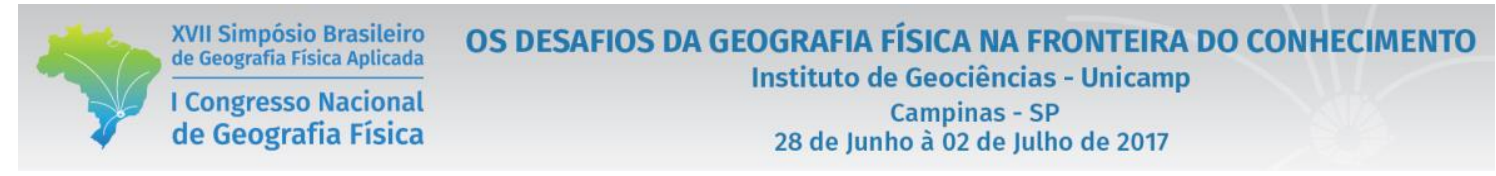

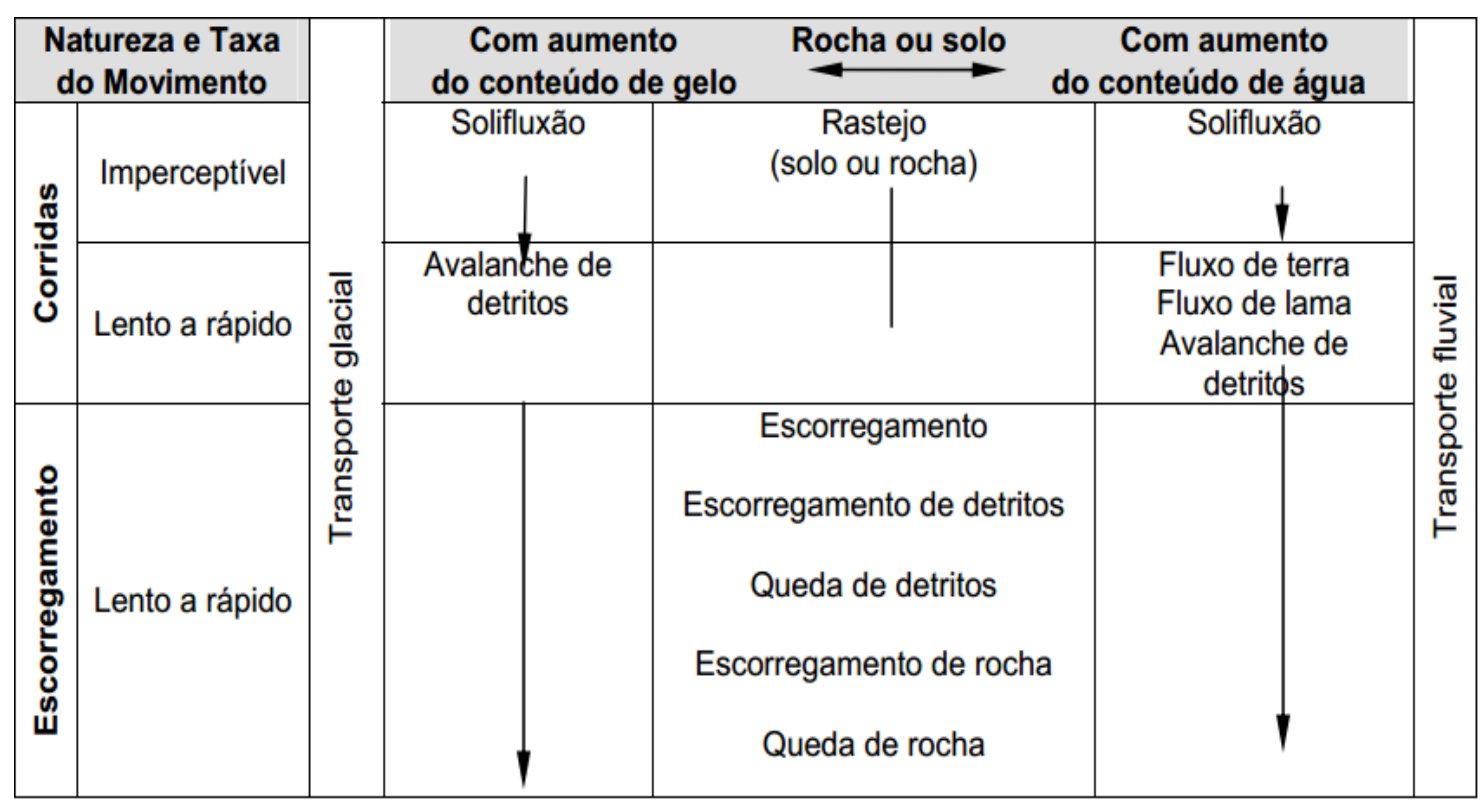

Sabendo que esses movimentos derivam principalmente de alguma ruptura da encosta e são desempenhadas por características naturais como a ação da precipitação pluviométrica, ou induzidas pela ação antrópica (desmatamento, poluição, aterros, cortes) os procedimentos metodológicos do presente trabalho pretendem observar áreas de suscetibilidade considerando a influencia da ação antrópica. Deste modo foram aplicados conhecimentos prévios estabelecidos a partir de literaturas no que faz referência aos processos e dinâmicas da encosta.

Contudo, foram determinados dois trabalhos de campo, o primeiro ocorrente no dia 03/05/2016 na encosta do morro Cechella e o segundo no dia 25/05/2016 no bairro Nova Santa Rita. As observações estão divididas em quatro amostragens por área de estudo, cujo objetivo era a visualização das dinâmicas superficiais da área de encosta do morro e posteriormente na área de cabeceira da drenagem correspondente ao arroio Cadena.

Ademais, as informações coletadas foram dispostas em tabelas no software Excel 2010 para posterior interpretação e compreensão da dinâmica superficial amostrada.

\section{RESULTADOS E DISCUSSÃO}

Os resultados e conclusões do trabalho estão organizados a partir da descrição dos dois trabalhos de campo realizados. 


\section{OS DESAFIOS DA GEOGRAFIA FÍSICA NA FRONTEIRA DO CONHECIMENTO \\ Instituto de Geociências - Unicamp \\ Campinas - SP \\ 28 de Junho à 02 de Julho de 2017}

3.1 Trabalho de campo nas cabeceiras do arroio Cadena

Na tabela 3 estão expostas as observações realizadas ao longo do percurso na localidade do bairro Nova Santa Marta, onde foram efetuadas quatro amostras principais.

Tabela 2. Amostragens realizadas nas encostas e cabeceiras do arroio Cadena de acordo com as características do terreno para cada amostra.

\begin{tabular}{|c|c|}
\hline Amostragens & Observações \\
\hline \multirow{6}{*}{$\begin{array}{l}\text { Primeira } \\
\text { Canal de } \\
\text { ordem }\end{array}$} & Processos erosivos intensos \\
\hline & Ocupação inadequada nos entornos \\
\hline & Solapamento \\
\hline & Acúmulo de lixo \\
\hline & Entornos bastante degradados \\
\hline & Vale em "V" \\
\hline \multirow{4}{*}{$\begin{array}{l}\text { Segunda amostra: } \\
\text { Área de encosta }\end{array}$} & Ocupações irregulares sem rede de esgoto \\
\hline & Área de nascente sem condições mínimas de preservação \\
\hline & Grandes áreas de depósitos de lixo \\
\hline & Substrato de arenito (base de rocha sedimentar) \\
\hline \multirow{4}{*}{$\begin{array}{l}\text { Terceira amostra: } \\
\text { Canal de primeira } \\
\text { ordem/nascente }\end{array}$} & Área de banhado \\
\hline & Descarte de resíduos diretamente no córrego \\
\hline & Áreas com solo descoberto \\
\hline & Poucas ruas asfaltadas \\
\hline \multirow{4}{*}{$\begin{array}{l}\text { Quarta amostra: } \\
\text { Divisor de águas }\end{array}$} & Área de erosão subterrânea \\
\hline & Solapamento abrindo pequenas ravinas \\
\hline & Contato de arenito com lamitos \\
\hline & Esgoto descarregado diretamente no canal fluvial \\
\hline
\end{tabular}

Fonte: Autores.

Como resultado de uma ocupação urbana irregular, o bairro Nova Santa Marta foi inicialmente formado a partir do "Movimento pela Moradia e Sem Teto" em 1991, apresenta condições de risco principalmente associadas à erosão das áreas de encosta. Este resultado está associado diretamente à precariedade das instalações residenciais (residências estabelecidas sobre cortes, aterros, em áreas de APP- Áreas de 
Preservação Permanente) e das condições de infraestrutura (ausência de esgotamento sanitário e fluvial). Diante as observações realizadas no trabalho de campo não há estruturas adequadas de adução, condução e escoamento da água da chuva e esgoto no bairro.

Em um trabalho na região oeste de Santa Maria, que engloba também o bairro Nova Santa Marta, Robaina et al. (2001) Robaina et al. (2001), apontam para as transformações que ocorreram na cobertura vegetal da região, por sua vez favorecendo os processos erosivos. Além disso, os autores ressaltam o escoamento da água por entre rochas com permeabilidade diferente, causando o solapamento das superfícies.

Numa análise geral do trabalho de campo, pode-se dizer que praticamente em todos os locais ocorre a deposição de lixo e descarte de esgoto a céu aberto ou diretamente no ambiente fluvial. Esse tipo de ação antrópica apresenta consequências imediatas sobre a dinâmica da encosta, uma vez que sobre a influência de grandes incidentes pluviométricos, pode vir a causar inundações devido o trancamento do canal fluvial, e movimentos de massa principalmente nas áreas mais próximas ao leito dos córregos. Na figura 4 pode-se visualizar a ocupação residencial próxima ao córrego bastante poluído.

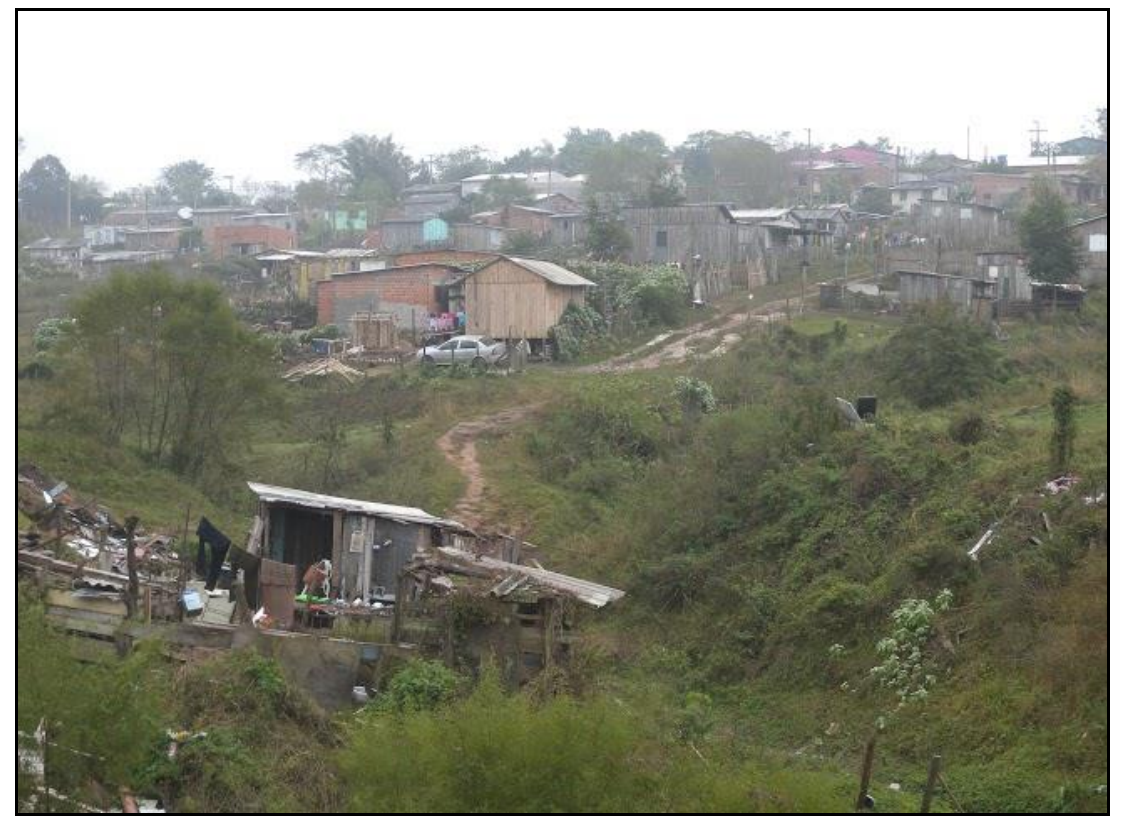

Figura 3. Ocupações residenciais irregulares próximas ao córrego afluente do arroio Cadena.

Como visto na terceira amostra, a ação antrópica sobre o uso do solo no bairro tem aumentado as áreas de solo pavimentado e descoberto de vegetação. Assim sendo, o processo de escoamento superficial torna-se mais concentrado favorecendo o desenvolvimento de ravinas e voçorocas, que estão associados ao sistema de drenagem. 
De maneira geral pode-se observar a ação das águas superficiais e subsuperficiais no processo de erosão interna nas cabeceiras de drenagem do bairro Nova Santa Marta. Esse tipo de processo teve como consequência o solapamento e queda dos taludes como evidenciado na quarta amostra do trabalho de campo. Sobreira (1998) constatou como determinantes as atividades antrópicas para reativação e aceleração desses processos erosivos, e conclui que na realidade são as ações humanas que provocam alterações num sistema frágil e de equilíbrio precário.

\subsection{Trabalho de campo encosta do morro Cechella}

Na tabela 2 estão dispostas as observações realizadas na encosta do morro seguindo a ordem das amostras. O ponto de partida se deu pela base do morro, cuja cota altimétrica registrada foi de 140 metros aproximadamente. De maneira geral, a ocupação é mais densa na base do morro, mas estende-se até, aproximadamente, 240 metros, na meia encosta. A porção situada mais próxima do topo ainda não está ocupada e encontra-se com cobertura vegetal de médio e grande porte.

Nessa ordem, as amostragens foram divididas ao longo do percurso de subida do morro, como ponto final, a pedreira que operava na extração do basalto, a tempo desativada.

Tabela 3. Amostragens realizadas na encosta do morro Cechella de acordo com as características do terreno para cada amostra.

\begin{tabular}{|c|c|}
\hline Amostragens & Observações \\
\hline \multirow[t]{4}{*}{$\begin{array}{l}\text { Primeira amostra: Vista de } \\
\text { talude }\end{array}$} & $\begin{array}{l}\text { Substrato formado por rocha arenítica que não possui grandes } \\
\text { descontinuidades }\end{array}$ \\
\hline & Vegetação com raízes espalhadas \\
\hline & Intensa ocorrência de processos erosivos \\
\hline & Acúmulo de lixo \\
\hline \multirow{4}{*}{$\begin{array}{lr}\text { Segunda amostra: } & \begin{array}{r}\text { Área } \\
\text { em }\end{array} \\
\text { inclinada } & \\
\text { aproximadamente } 30^{\circ} & \end{array}$} & Instalação residencial é estabelecida através de cortes \\
\hline & Patamares de corte \\
\hline & Vegetação de grande e pequeno porte \\
\hline & Solo descoberto \\
\hline \multirow{2}{*}{$\begin{array}{lcr}\text { Terceira } & \text { amostra: Área } \\
\text { ocupada } & \text { e } & \text { bastante } \\
\text { inclinada } & & \end{array}$} & Material lançado de pequeno porte \\
\hline & Menos ocupação e maior predominância de coberturas vegetais \\
\hline \multirow{2}{*}{$\begin{array}{l}\text { Quarta amostra: Vista do } \\
\text { topo da encosta }\end{array}$} & Rocha vulcânica-basaltos \\
\hline & Derrames verticais \\
\hline
\end{tabular}

Fonte: Autores. 
Diante as observações realizadas, ficou evidente a existência do risco de movimentos de massa na encosta do morro Cechella. Este resultado esteve associado principalmente as ocupações caracterizadas por condições irregulares de instalação. Além disso, pode-se observar várias residências estabelecidas por meio da realização de cortes na encosta cuja inclinação alcançava aproximadamente $30^{\circ}$, como evidenciado na tabela 2 , na segunda amostra.

$\mathrm{Na}$ primeira amostra já ficaram evidentes o acúmulo de material residual doméstico e ocorrência de processos erosivos com elevada intensidade, favorecendo a possibilidade de escorregamentos. Além disso, pode visualizar a vegetação arbórea com raízes espalhadas e não muito profundas, sendo assim outro fator de risco, principalmente para as residências.

Por apresentar vertentes íngremes e rochas expostas, a ação da água sobre a encosta pode vir a ser um fator de risco à medida que penetra nas fraturas das rochas desencadeando tombamentos e quedas de blocos de derrames verticais como apresentado na tabela 2, quarta parada.

Pode-se vislumbrar a ocorrência de processos erosivos na encosta derivados principalmente da retirada da vegetação. Como consequência, raízes de árvores apresentam-se expostas favorecendo para que ocorra desestabilização das mesmas e no pior dos casos, atingir as moradias. Na figura 5 encontram-se duas moradias (Imagem A e imagem B) nesse tipo de situação.

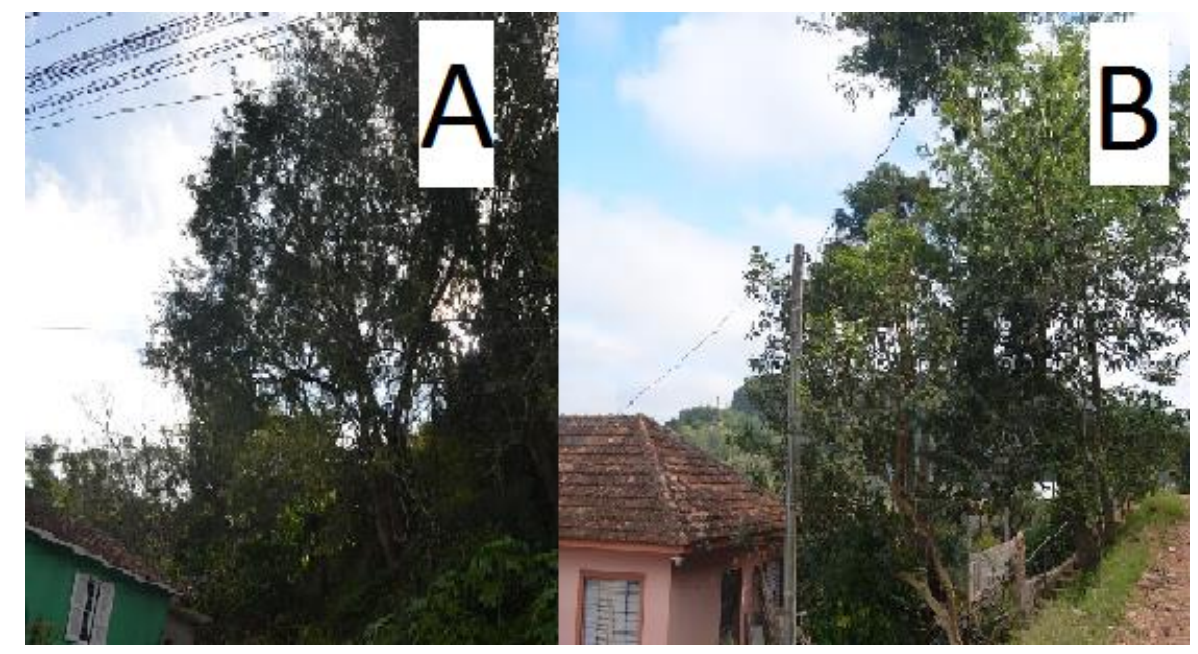

Figura 4. Moradias em situação de risco na encosta do morro Cechella, devido ao possível tombamento da vegetação arbórea. 
De maneira geral, observou-se que grande parte das moradias na encosta do morro apresenta a implementação de muros de contenção, sendo o talude coberto por vegetação em alguns casos plantada pelos próprios moradores da vila.

Em um estudo realizado na cidade de Santa Maria, Maciel Filho (1990) apresenta a carta geotécnica dos condicionantes de ocupação das áreas. Como resultado do trabalho, o autor concluiu que a área correspondente à encosta oeste do morro Cechella (vila Bela Vista) encontra-se em condições impróprias para a ocupação humana.

\section{CONSIDERAÇÕES FINAIS}

Diante os objetivos estabelecidos pelo trabalho em conjunto com as observações realizadas em trabalho de campo pode-se concluir que os principais processos de instabilidade das encostas são derivados de ações antrópicas. Na maioria dos casos observados, as ocupações desrespeitam a capacidade de uso do solo adotando práticas inadequadas para instalação das moradias.

Sobre essa perspectiva, se faz necessária a utilização de medidas preventivas que visam garantir o equilíbrio da natureza e uso do solo. A ocupação das encostas necessita de planejamento para que sejam minimizados os impactos negativos à área e evitando a degradação do solo e consequentes movimentos de massa.

Ressalta-se a importância de levantamentos de séries históricas de ocupação da encosta para que seja efetivado um planejamento adequado. Desta forma, será possível realizar um diagnóstico sobre as dinâmicas da encosta sobre a influência da ação humana.

\section{AGRADECIMENTOS}

Os autores agradecem ao professor Dr. Luís Roberto Robaina pela condução às atividades de campo e suporte.

\section{BIBLIOGRAFIA}

BIMBI, E. Conselho Federal de Engenharia, Arquitetura e Agronomia. Revista Confea. Disponível em: <http://www.confea.org.br/revista/materiais/edicao_20/materia_04/materia.asp. Acesso em 20 de junho de 2016.

CUNHA, M. A. (coord.). Manual Ocupação de Encostas. São Paulo: Instituto de Pesquisas Tecnológicas, 1991. 
DAL'ASTA, A. P.; RECKZIEGEL, B. W.; ROBAINA, L. E. de S. Análise de Áreas de Risco Geomorfológico em Santa Maria-RS: o caso do Morro Cechella. In: SIMPÓSIO BRASILEIRO DE GEOGRAFIA FÍSICA APLICADA, 11, 2005, São Paulo. 53 B.goiano.geogr, Goiânia, v. 30, n. 2. p. 43-53. 2010 Artigo BGG Anais eletrônicos... São Paulo: USP, 2005. Acesso em: 17 jun. 2016.

GUERRA, A. J. T., ARAUJO, G. H. S., ALMEIDA, J. R.. Gestão Ambiental de Áreas Degradadas. Ed. Bertrand Brasil. Rio de Janeiro 2005.

MACEDO, E. S.. DESASTRES NATURAIS: CAUSAS E CONSEQÜÊNCIAS.Geociênc. (São Paulo), São Paulo, v. 27 , n. 1, jan. 2008 . Disponível em http://ppegeo.igc.usp.br/scielo.php?script=sci_arttext\&pid=S0101$822008000100022 \& \operatorname{lng}=$ pt\&nrm=iso $>$. acessos em 20 jun. 2016.

MACIEL FILHO, C. L. Carta Geotécnica de Santa Maria. Santa Maria: Imprensa Universitária UFSM, 1990.

RECKZIEGEL, B. W., DE SOUZA ROBAINA, L. E., MENGUE, V. P. Urbanization and aceleration the erosion process in Santa Maria city-RS-Brasil. Sociedade \& Natureza, v. 1, n. 1, p. 772-780, 2005.

ROBAINA, L. E. de S.; BERGER, M.; CRISTO, S. S. V. de; DE PAULA, P. M. Análise dos Ambientes Urbanos de Risco do Município de Santa Maria-RS. Ciência e Natura: Revista do Centro de Ciências Naturais e Exatas. Santa Maria: ed. UFSM, v. 23, dez. 2001, p. 139-152.

SOBREIRA, F. G. Estudo das erosões de Cachoeira do Campo/MG. Relatório FAPEMIG, UFOP/EM/DEGEO, 1998. 